\title{
Application of Variance Analyses Comparison in Seismic Damage Assessment of Masonry Buildings Using Three Simplified Indexes
}

\author{
Qiwang Su, ${ }^{1}$ Gaochuang Cai, ${ }^{2}$ and Hervé Degée ${ }^{2}$ \\ ${ }^{1}$ School of Civil Engineering, Southwest Jiaotong University, Chengdu, Sichuan 610031, China \\ ${ }^{2}$ Construction Engineering Research Group, Faculty of Engineering and Technology, Hasselt University, Diepenbeek 3590, Belgium \\ Correspondence should be addressed to Gaochuang Cai; gc_cai@yahoo.co.jp
}

Received 8 August 2016; Revised 19 December 2016; Accepted 24 January 2017; Published 20 February 2017

Academic Editor: Giuseppe Quaranta

Copyright (C) 2017 Qiwang Su et al. This is an open access article distributed under the Creative Commons Attribution License, which permits unrestricted use, distribution, and reproduction in any medium, provided the original work is properly cited.

\begin{abstract}
The reasonable assessment of potential damage type of masonry structures in seismic-prone zone is very significant to strengthen existing masonry structures and guide the construction of the new building. The primary objective of the study is to propose and determine a reasonable assessment index to predict the damage type of masonry structures in different seismic intensity zones using the survey results of the 2008 Wenchuan earthquake and variance analyses comparison methods. Three potential theory assessment indexes are considered in the evaluation of damage of masonry structures, including wall density index $I_{w}$, strength index $I_{s q}$, and combined index $I_{s d}$. In order to compare the feasibility of the three indexes, One-way analysis of variance and Scheffe's method were used for in-depth discussion. Based on the proposed assessment indexes, further analyses and recommendations were provided. Results show the combined index $I_{s d}$ has a high potential to predict the damage levels of masonry structures. Based on the study, several recommendations were provided for the masonry structures in seismic-prone zones.
\end{abstract}

\section{Introduction}

Earthquake is considered as one of the most serious natural disasters that cause immeasurable damage to the building structures and our living environment. China is one of the countries that has a number of seismic active zones in the world and frequently suffers from catastrophic earthquake such as the 2008 Wenchuan earthquake $(8.0 \mathrm{Mw})$ which has caused 69197 dead and 374176 injured people with 18222 listed as missing as of July 2008 [1]. National Police Agency of Japan [2] has also confirmed that there were 15894 dead, 6152 injured, and 2562 homeless people during the 2011 Great East Japan Earthquake (9.0-9.1 Mw). The World Bank has estimated that the economic cost caused by this earthquake was US $\$ 235$ billion, making it the costliest natural disaster in the world history [3]. In the seismic-prone regions, it had been a consensus that the main seismic behaviour of building structures should be predicted precisely as much as possible. This is not only to understand the potential damage of new structures to guide our design works, but also in order to provide a series of technological supports to strengthen existing structures to resist a future coming earthquake. On the other hand, as one of common structural types, masonry buildings are widely used in a number of countries such as Europe, Chile, and China $[4,5]$, for its advantages including energy saving, easy availability of materials, and low construction cost. Generally, masonry structure usually is made of brick and mortar and can be divided mainly into unreinforced masonry (URM), confined masonry (CM) and reinforced masonry (RM) structures [6]. However, there are also a number of masonry structures constructed without referring to any design codes or standards, such as in the rural regions of developing countries. Consequently, a reliable assessment method is very important to enhance the seismic safety of the structures and predict their potential damage. It is also very helpful and meaningful to retrofit and strengthen the existing masonry structures [7-9].

In the past three decades, many efforts have been performed to understand the structural characteristic of masonry structures and to establish reasonable masonry 
TABLE 1: Damage categories of masonry wall.

\begin{tabular}{lcc}
\hline Damage categories & Damage description: cracking and collapse & Treatments and measures \\
\hline Slight or no damage & $\begin{array}{c}\text { No obvious damage occurs in any wall pieces, or the number of } \\
\text { the wall pieces with small cracks is less than } 50 \% \text { of all wall } \\
\text { pieces in the seismic direction }\end{array}$ & Small-scale repair such as surface repair \\
\hline & $\begin{array}{c}\text { The number of the wall pieces with small cracks is more than } \\
50 \% \text { of the total walls in the seismic direction or the number of } \\
\text { the wall pieces with large cracks is less than 50\% of the total } \\
\text { wall, or the number of wall pieces with severe cracks is under } \\
10 \% \text { of the total one }\end{array}$ & $\begin{array}{c}\text { Large-scale repair including partial } \\
\text { change }\end{array}$ \\
$\begin{array}{c}\text { Moderate damage } \\
\text { The number of wall pieces with large cracks is more than } 50 \% \text { of } \\
\text { all wall pieces in the seismic direction, or the number of wall } \\
\text { pieces having severe cracks ranges from } 10 \% \text { to } 50 \% \text { of the total } \\
\text { walls in the seismic direction }\end{array}$ & Total/partial reconstruction \\
\hline & $\begin{array}{c}\text { The number of wall pieces having the severe cracks, broken or } \\
\text { collapse is more than } 50 \% \text { of the total walls in the seismic } \\
\text { direction; or total collapse of building structure }\end{array}$ & Total demolition and reconstruction \\
\hline
\end{tabular}

material models and effective finite analysis methods for their simulation and design [7, 10-13]. These studies usually involve some small-scale experimental studies and numerical simulation based on various finite analysis models [14-16]. Even though quite a few numerical simulation analyses have presented good evaluation results, earthquake filed investigations are limited and expected. Among them, several studies have attempted to develop simple seismic safety assessment indexes for URM structures [17-20]. For instance, Lourenço et al. [17] proposed three simplified indexes to assess the safety of the historical URM buildings under seismic loads. On the basis of their study, a few studies have been reported to make some modifications to these three indexes for URM or to present some combined analysis methods using the three indexes and finite element method to characterize CM structures $[21,22]$. Besides, some vulnerability assessment methods based on uncertain structural systems analysis have been developed recently [18-20]. A few methods have been proposed which are suitable for both URM and CM structures. Moreover, due to the lack of seismic field survey data, there are a few studies (e.g., $[17,21])$ that involved the relationship between assessment indexes and actual damage of URM/CM structures. In addition, several previous studies [23, 24] have confirmed that the confinement members of the structural masonry walls in CM structures can prevent effectively the collapse of masonry wall and then improve the seismic resistance of the whole structure system. The enhancement effect of the confinement elements on the deformation and resistance of masonry wall has been illustrated which then improves the seismic behaviour of the whole structure, as in the terms of structural ultimate failure modes. One more important thing is that up to now the primary assessment procedures of masonry structures in most current seismic design codes such as the ones in China and Latin America are established only on the basis of the structural strength design theory which was used to design them. It is suspectable and needs to be improved for enhancing the vulnerability of masonry structures.
Therefore, the primary objective of the study is to propose reasonable assessment indexes to predict the potential damage type of masonry structures under seismic effects using the survey results of a number of masonry buildings in the 2008 Wenchuan earthquake. For this, some potential theory assessment indexes are considered including wall-related index, strength-related index, and a combined index considering the effect of confinement elements on masonry walls. Detailed mathematical statistic comparison methods are used to determine which index is more appropriate to assess the damage of masonry structures. Based on the proposed assessment index, some further analyses and recommendations are provided.

\section{Damage Categories of Masonry Structures during an Earthquake}

Generally, due to the fact that the thickness and openings ratio of masonry wall at each floor are identical, the stiffness of masonry structural members at each floor is initially the same. When the structure is subjected to lateral shearing force caused by earthquake effects, the main damage of masonry buildings usually takes place at the first storey. This behaviour has been confirmed by the previous field surveyed results and other researcher [25]. Therefore, the reasonable evaluation of the damage level of bottom walls is considered as a very important process to assess the potential damage degree of whole masonry building under earthquake loads. The damage degrees are determined and divided into four levels according to the damage situation of the wall pieces at the first floor, including fine cracks (width $\leqq 1.5 \mathrm{~mm}$ ), large cracks (width $\geqq 1.5 \mathrm{~mm}$ ), severe cracks (width $\geqq 3.0 \mathrm{~mm}$ ), and collapse [26]. The details of these damage categories are listed in Table 1 while some representative damage degrees are presented in Figure 1. 

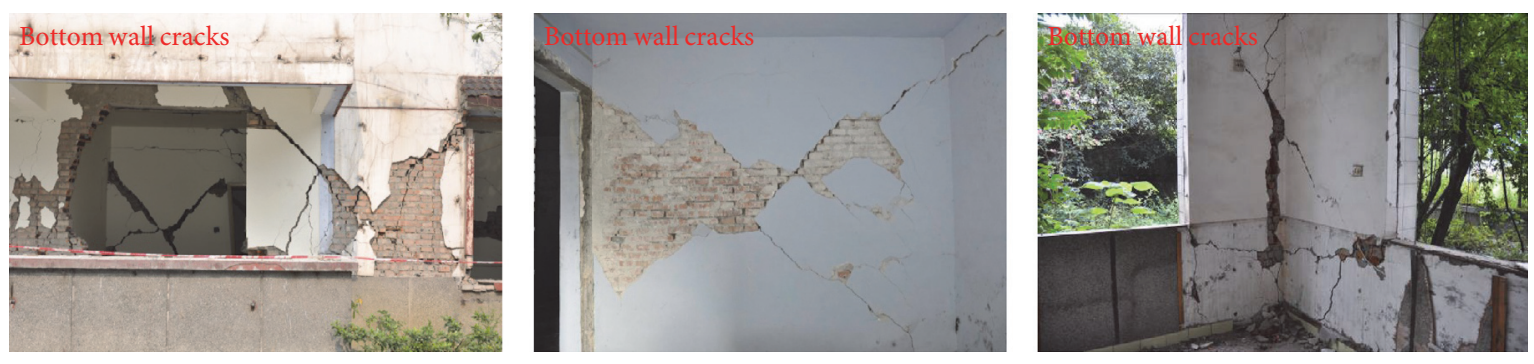

FIGURE 1: Damage of bottom masonry walls during the 2008 Wenchuan earthquake.

\section{Potential Damage Assessment Indexes for Masonry Structures}

The earthquake-resistance performance of masonry buildings significantly depends on the lateral resistance capacity of masonry walls at the earthquake direction. This means that adequate walls should be provided in each potential earthquake direction of building structures. On the other hand, however, the seismic behaviour of CM structures consisting of confined members such as RC tie columns and beams is significantly affected by their seismic behaviour and strength properties of the masonry walls in the earthquake direction. Therefore, the reasonable assessment indexes to predict the potential damage of masonry structures should take into account the structural strength or the effect of confinement elements or both of them. In this study, three potential assessment indexes are considered to evaluate the damage degree of masonry structures, that is, wall density index in seismic direction $I_{w}$, strength index $I_{s q}$, and combined index $I_{s d}$ considering both strength and the effect of confinement elements. The section introduces a summary of their definitions and relevant concepts.

3.1. Wall Density per Unit Floor $I_{w}$. According to the field survey obtained from one of the authors of the paper, the more masonry walls at each floor there are, the higher seismic resistance capacity the masonry structure can resist, especially for the URM structures. In this study, as reported by other researchers [16, 17], wall density per unit floor has been used to quantify the number of walls at each floor of the structure. Due to the fact that the masonry walls and tie columns in masonry structures are the main shear resistance members of masonry structures, the wall density per unit floor index $\left(I_{w}\right)$ is a ratio of the total cross-section areas of all walls at $i$ th direction to the total area of all the floors in structures, which is given by

$$
I_{w i}=\frac{A_{w i}+A_{c i}}{n A_{f t}},
$$

where $A_{w i}$ is the total cross-section areas of all walls in the $i$ th direction; $A_{c i}$ is the total horizontal cross-section areas of all RC tie columns at the $i$ th direction, which will be taken as zero for URM structures; $A_{f t}$ is the total area of each floor of masonry structures; and $n$ is the number of storeys.

During the calculation of this nondimensional index $I_{w}$, all masonry walls and RC tie columns are considered as the main members to resist the seismic shear forces of structures. Meanwhile, RC tie columns are roughly taken as a part of masonry walls in this process. It is very suitable and helpful to some masonry buildings which lack the detailed information of used construction materials' strength. In order to predict the potential seismic damage levels of masonry walls, it is necessary to analyse and calibrate the relationship between $I_{w}$ and the actual damage levels obtained from field survey data of masonry buildings.

3.2. Strength Index $I_{s q}$. In theory, $I_{w}$ might lowly evaluate the seismic safety and damage of the masonry structures using high strength masonry materials. Therefore, the strength index of all vertical members at each floor could be an alternative assessment method that considers both wall density and the mechanical properties of wall materials. For example, the lateral resistance capacity of the vertical members of masonry structure at the base floor affects significantly the seismic resistance of the whole masonry building. Therefore, in lowrise wall bearing structure system, referring to the study result of Japan Building Disaster Prevention Association [27], for masonry structure, the strength index $C_{j}$ of the vertical members (wall and tie column) in certain direction is expressed as

$$
C_{j}=\frac{Q_{j}}{\sum w} .
$$

The equation shows that the factor $C_{j}$ is determined mainly by the used material strength and the horizontal cross-section of the calculated buildings. Therefore, for the wall and tie columns that can be considered as a group in masonry structures, the structural strength factor $I_{s q}$ in the $i$ th direction is recommended in the study and given by

$$
\begin{aligned}
I_{s q i} & =C_{j}=\frac{A_{w i} \tau_{w}+A_{c i} \tau_{c}}{w \sum A_{f}}=\frac{A_{w i} \tau_{w}+A_{c i} \tau_{c}}{w n A_{f t}}, \\
\tau_{w} & =\xi_{N} f_{v k, s w} .
\end{aligned}
$$

$I_{s q i}$ is strength factor in the $i$ th direction; $Q_{j}$ is lateral resistance of vertical members in group $j$ and in the $i$ th direction, calculated as $\tau_{j} A_{j} ; \tau_{j}$ is standard shear strength of the vertical members of group $j$ in the $i$ th direction; $A_{j}$ is the effective area of vertical members of group $j$ at the calculation floor; $\tau_{c}$ is shear strength of tie columns in masonry structure; $\tau_{w}$ is shear strength of masonry wall; $\xi_{N}$ is effect factor of normal shear stress of masonry structures; $f_{v k, s w}$ is standard shear 
strength of masonry wall; $w$ is gravity load per unit area of masonry structure, which was taken as $12000 \mathrm{~Pa} ; \sum A_{f}$ is the total area of the calculation floor and the ones over this floor.

3.3. Combined Assessment Index $I_{s d}$. In theory, wall density index $I_{w}$ and strength index $I_{s q}$ can evaluate the damage of URM structures well; however, they are not good for CM structures. Previous research (e.g., [23]) reported that the enhancement effect of confinement elements of $\mathrm{CM}$ buildings should be taken into account when predicting the seismic damage of this confined masonry structures. The two indexes $I_{w}$ or $I_{s q}$ may be improved further into a more effective index to assess the potential damage of masonry structures including URMs and CMs when considering the enhancement effect of confinement elements. Therefore, the study proposes a combined index considering masonry structural strength and the enhancement effects of confinement elements together. Using the above proposed strength index and referring to the seismic evaluation theory of existing RC structures in Japan Building Disaster Prevention Association [28], a combined index $I_{s d}$ in the $i$ th direction considering the effects of strength and confinement's effects can be defined as

$$
I_{s d i}=R_{i} I_{s q_{i}}
$$

Comparing with URM buildings, CM structures usually include RC tie columns and beams which both have a significant effect on the seismic behaviour of the total structures, in particular in structural deformation and lateral resistance performance. As a consequence, considering the effect of RC tie columns, tie beams, and rigid slab on total structural seismic behaviour, an assessment factor is proposed to evaluate the enhancement effectiveness of the confinement elements in confined masonry buildings, which is called the enhancement factor of confinement elements in the $i$ th direction $R_{i}$ and expressed as follows:

$$
R_{i}=\gamma_{c i} \gamma_{b i} \gamma_{s i}
$$

where $R_{i}$ is the enhancement factor of confinement elements in confined masonry structures in the $i$ th direction; $\gamma_{c i}, \gamma_{b i}$, and $\gamma_{s i}$ are three coefficients considering, respectively, the impacts of tie columns, tie beams, and rigid floor slabs on the structural performance of the whole structure in the $i$ th direction. To understand the action of the three kinds of confinement on the masonry wall, a confined masonry structure was supposed to be put upside down. If no confinement values are set, the whole masonry system could collapse or just have limited seismic capacity. Therefore, in this study, they are defined simply as the corresponding volume ratios to masonry wall and expressed by (6)-(8). For URM buildings, $\gamma_{c i}$ and $\gamma_{b i}$ both are equal to 1.0. Meanwhile, the value of $\gamma_{s i}$ is also equal to 1.0 when precast RC slabs without strong connection are used in floor because of the insufficient of structural integrity. However, if the precast RC slabs have a good connection such as using concrete reinforced with hooked/welded steel connection, the value of $\gamma_{s}$ should be calculated as per (8).
(1) $\gamma_{c i}$ is the enhancement ratio of RC tie columns to masonry wall:

$$
\gamma_{c i}=1+\frac{n_{1} H_{c i} A_{c i}}{n_{1} H_{c i} A_{c i}+H_{w i} A_{w i}} .
$$

(2) $\gamma_{b i}$ is the enhancement ratio of RC tie beam to masonry wall:

$$
\gamma_{b i}=1+\frac{n_{1} \sum_{j=1}^{m} L_{q i, j} A_{q i, j}}{n_{1} \sum_{j=1}^{m} L_{q i, j} A_{q i, j}+\sum_{j=1}^{m} L_{w i, j} A_{w y i, j}} .
$$

(3) $\gamma_{s i}$ is the enhancement ratio of RC floor slab to the masonry structures:

$$
\gamma_{s i}=1+\frac{n_{1} \sum_{j-1}^{m} A_{b, j} h_{b, j}}{\sum_{j=1}^{m} V_{j}},
$$

where $H_{c i}$ and $H_{w i}$ are the total vertical height of tie columns and of masonry walls in the $i$ th direction, respectively; $A_{q i, j}$ is the total vertical cross-section areas of tie beams at the $j$ th floor in the $i$ th direction; $L_{q i j}$ is the average horizontal length of tie beams at the $j$ th floor in the $i$ th direction; $A_{w y i, j}$ is the total vertical cross-section areas of masonry walls at the $j$ th floor in the $i$ th direction; $L_{w y i, j}$ is the average horizontal length of masonry walls at the $j$ th floor at the $i$ th direction; $A_{b, j}$ is the in-plane area of floor slab (which has been reliably connected) at the $j$ th floor; $h_{b, j}$ is the thickness of floor slab at the $j$ th floor; $m$ is the total of floors; $V_{j}$ is the total volume of the $j$ th floor which is calculated using the height $\left(h_{j}\right)$ and in-plane area $\left(A_{f, j}\right)$ of the $j$ th floor, respectively, as follows:

$$
V_{j}=n_{1} A_{b, j} h_{b, j}+\left(h_{j}-h_{b, j}\right) A_{f, j} .
$$

Meanwhile, $n_{1}$ is the shear modules ratio of concrete element to masonry wall in masonry structure. This factor can be used to explain the different structural behaviour and damage degree of the buildings with the same structural geometry but with sensible difference regarding mechanical ratio of rebar on nodes. In order to calculate the factor $n_{1}$, the enhancement effect of confined elements on seismic behaviour of CM buildings should be understood clearly. For example, to understand the effect of the tie column elements to the seismic performance of the whole buildings, masonry building is reversed vertically. If there are no vertical confinement elements such as URM, the vertical connection strength of the building will be determined by the axial ultimate tensile strength of wall. In CM building, however, tie columns significantly enhance the vertical integrity of the structures. As a result, $\gamma_{c i}, \gamma_{b i}$, and $\gamma_{s i}$ also represent an increase ratio of the vertical, horizontal, and spatial connection strength. The factor $n_{1}$ can be expressed as

$$
n_{1}=\frac{\left(f_{t k c}-f_{t k m}\right)}{f_{t k m}}
$$

where $f_{t k m}$ and $f_{t k c}$ are the characteristic axial tensile strengths of masonry units and tie columns, respectively. According to 


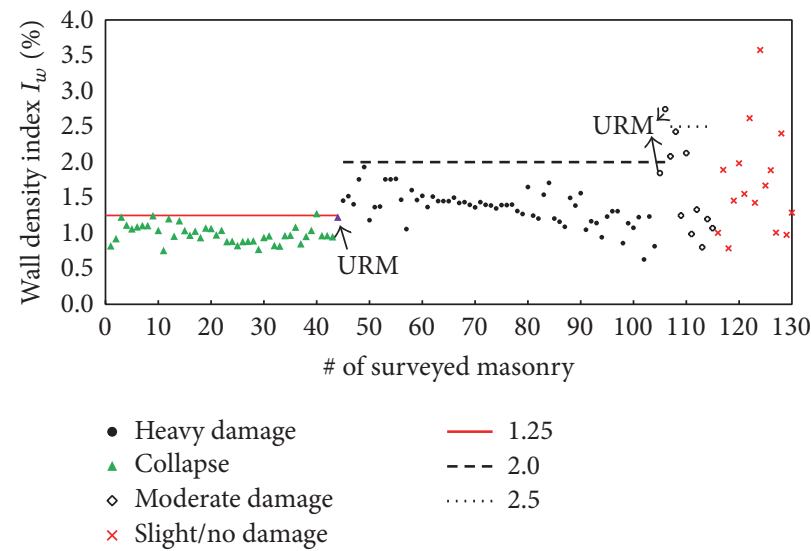

FIGURE 2: $I_{w}$ and damage categories of masonry structures at seismic intensity IX zone.

the axial tensile calculation theory of reinforced concrete and the definition of $f_{t k c}$, a simplified mechanical equilibrium in CM building is obtained as follows:

$$
f_{t k c} A_{c}=f_{y k} A_{s}
$$

where $f_{y k}$ is the tensile strength of steel rebar in tie column; $A_{s}$ is the sectional areas of steel rebar in per tie column (almost the same in the same building); $A_{c}$ is the sectional area of per tie column; According to (11), $f_{t k c}$ is obtained which is then used to calculate the factor $n_{1}$. For $f_{t k m}$ that is determined by the tensile strength of mortar which can be gained by the related codes such as in [4], the ratio of $f_{t k c}$ to $f_{t k m}$ is close to the ratio of ultimate shear strength of concrete to masonry.

\section{Three Proposed Indexes versus Actual Damage Degree of Masonry Structures}

Through investigating 130 masonry buildings (mainly including CM) in the seismic intensity IX zone (modified Mercalli scale) during the 2008 Wenchuan earthquake, the relationships between the proposed indexes and the damage degree surveyed building are studied, respectively. In the inspected buildings, the tie columns have a width of $240 \mathrm{~mm}$ and a height of $240 \mathrm{~mm}$; both are equal to the thickness of masonry wall. All tie columns usually were arranged wall joints, corners, and margin of openings. They generally were reinforced by $10 \mathrm{~mm}$ deformed steel rebar (about $235 \mathrm{MPa}$ yielding strength) and confined by diameter $6 \mathrm{~mm}$ stirrup with a spacing of $200 \mathrm{~mm}$ per code at that time. These reinforcements have been connected well in the nodes of these inspected buildings, which guarantee the deformation and mechanical performance of RC confined members.

(1) Wall Density per Unit Floor $I_{w}$. Figure 2 shows the relationships between $I_{w}$ and the actual damage categories of masonry structures at seismic intensity IX zone, respectively. Results present that this index distinguishes these different damage degrees of masonry structures well. When CM buildings are at the high seismic intensity zone, heavy damage and moderate damage occurred in the building with the indexes
$I_{w}$ of less than $2.0 \%$ and $2.5 \%$, respectively. On the other hand, there are no masonry structures which had failed as collapse damage when the $I_{w}$ of buildings is larger than $1.25 \%$, both URM and CM buildings. In addition, as shown in the figure, the increase of $I_{w}$ has resulted in an obvious decrease in the damage degree of these masonry structures and presents a clear difference between different damage. This indicates that index $I_{w}$ could be applied to distinguish the potential damage type of masonry structures. Taking the above presented $I_{w}$ levels as the critical values corresponding to different damage degrees, the simple wall density index $I_{w}$ is very helpful to assess potential damage categories of CM structures, especially for the ones with limited recorded information.

(2) Strength Index $I_{s q}$. In order to clearly present the relationship between damage degree and $I_{s q}$ of masonry buildings at same seismic intensity zone, two simplified factor are introduced, that is, $x$ and $y$. Here, $x$ is a ratio of total wall area in seismic direction to the total plane area of the calculated floor and its upper floors, which is defined as

$$
x=\frac{A_{w}}{\sum A_{f}} .
$$

On the other hand, $y$ is a ratio of the total weight of the calculated floor and its upper floors to the total plane area of tie columns and walls in seismic direction, which represents the average axial compressive strength of these masonry walls in this direction, which is defined as (11). In this equation, the self-weight of per unit volume masonry wall is taken as a constant value (0.012 $\mathrm{MPa})$ according to Chinese code [4].

$$
\left.y=\frac{0.012 \sum A_{f}}{\left(A_{w}+A_{c}\right)} \quad \text { (in } \mathrm{MPa}\right) .
$$

Therefore, using (12) and (13), (2) can be expressed in the form of

$$
y=\frac{0.0084}{\left(0.012 I_{s q}+0.35 x\right)} \quad(\text { in } \mathrm{MPa}) .
$$

According to the (12), as shown in Figure 3, the relationship between $x$ and $y$ can be attained to express the relationship 

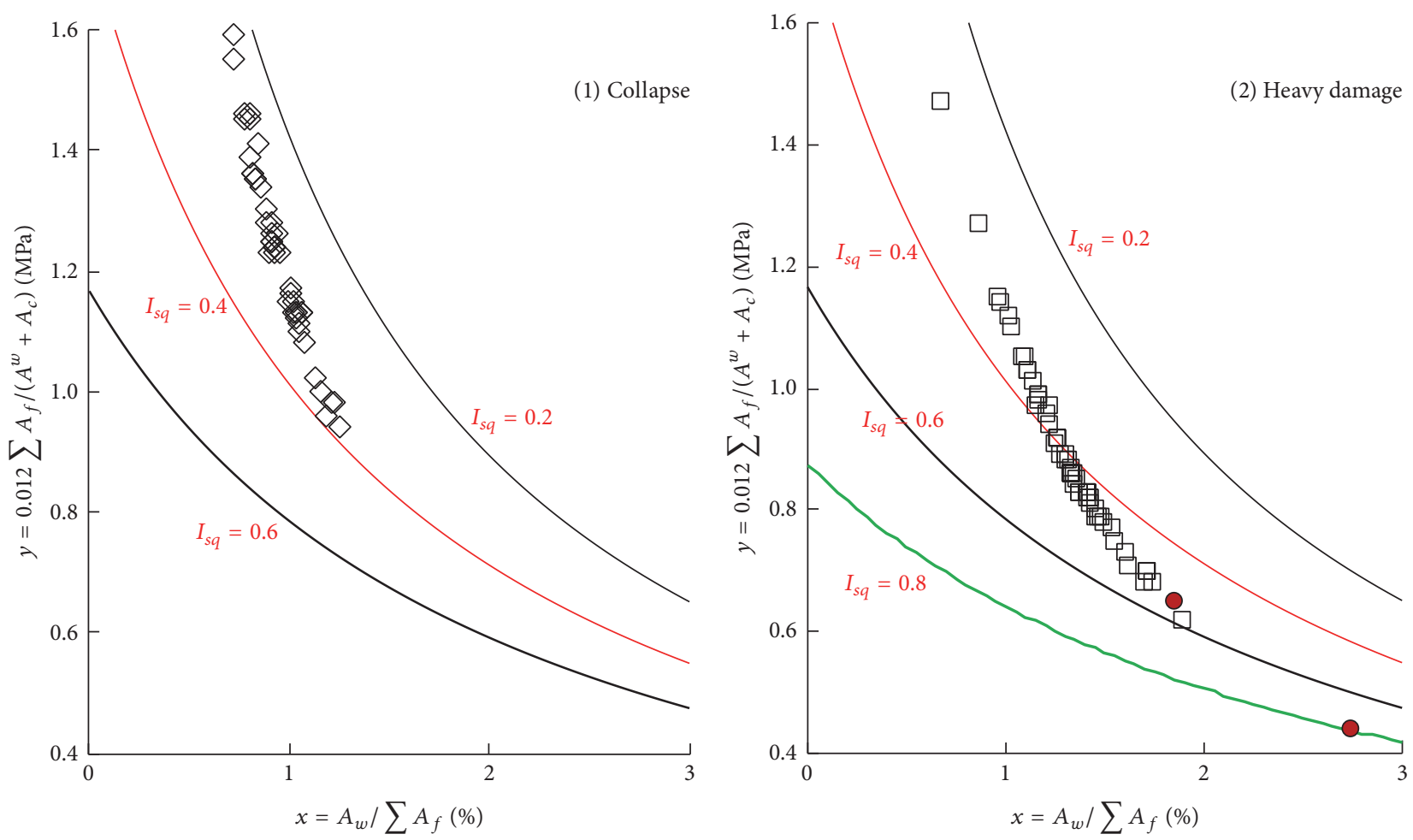

$\diamond \mathrm{CMs}$

$\square \mathrm{CMs}$

- URM



$\square \mathrm{CMs}$

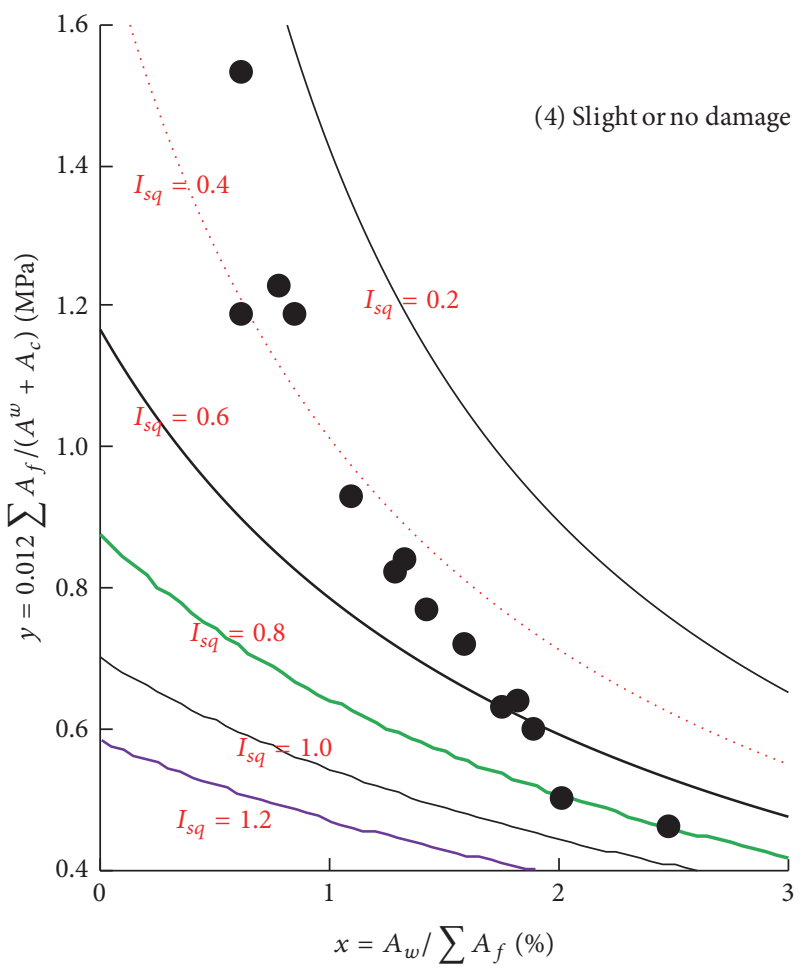

- $\mathrm{CMs}$

FIgURE 3: $I_{s q}$ and damage levels of the masonry structures in seismic intensity IX zone. 
damage degree and $I_{s q}$ of masonry buildings, which comes from the seismic survey data of the 2008 Wenchuan earthquake (in intensity IX zone). The results show that the critical values of the index $I_{s q}$ provide a good distinguishing method for assessing the potential damage degree of the masonry buildings. Based on this figure, the masonry structures for most CM buildings with collapse damage were observed when the values of $I_{s q}$ range from 0.2 to 0.4 . Similarly, the heavy damage and moderate damage are, respectively, observed when the index $I_{s q}$ ranges from 0.4 to 0.6 and from 0.4 to 0.8 , respectively. When the values of $I_{s q}$ range from 0.6 to 0.8 , heavy damage was confirmed in some URM structures, even though the number of the kinds of URM is small.

(3) Combined Index $I_{s d}$. To study the relationship between index $I_{s d}$ and damage level of masonry structures, the same procedures and field investigation data as the ones of indexes $I_{w}$ and $I_{s q}$ are used. Comparing with the process to calculate these two indexes, more detailed information of masonry buildings are required for index $I_{s d}$, including mainly the detailed information of tie columns, tie beams, and floor slab. The relationships between $I_{s d}$ and the damage categories of these investigated masonry structures are presented in Figure 4 . There is a decline in the damage degree of the masonry structures as index $I_{s d}$ increases. In addition, the results plotted as Figure 4 shows that the damage categories of these masonry building are differentiated by index $I_{s d}$ more easily and clearly. For the collapse buildings, all the values of $I_{s d}$ are not greater than 0.6 and the values of the strength index $I_{s q}$ for these building also are less than 0.4 . Similarly, for the $\mathrm{CM}$ buildings with heavy damage and moderate damage, the corresponding values of their index $I_{s d}$ are not greater than 0.8 and 1.02 , respectively. The results imply that the combined index also presents a high potential to be applied to assess the damage levels of masonry structures in seismic intensity IX zone.

\section{Detailed Mathematical Statistic Comparison}

The above comparisons indicate that index $I_{s d}$ presents a higher rationality and feasibility to predict the potential damage of masonry structures. However, more detailed comparison between these three indexes is expected, for it is good to support the relevant provisions and codes formation based on a more quantitative comparison. Meanwhile, for the view of large sample database, the appearance of the four types of seismic damage of masonry structures is approximately normal distribution. If considering all single samples with the same damage type as a sample group, the differences between these four groups should be reflected on each proposed assessment indexes. Therefore, the obvious difference or distinguishable degree of the assessment indexes can be used to evaluate the superiority of these assessment indexes. It should be noted that the results regarding URM structures in the paper may represent a limited behaviour for the number of URM buildings which is quite small in the seismic intensity IX zone of China. Form the view of mathematical statistics, in order to study whether the control variables (here, four seismic damage levels) had a significant impact on observed variables (three proposed indexes in this study), there are mainly two methods, that is, a single factor analysis and multivariate analysis.

5.1. One-Way Analysis of Variance (ANOVA) Method. In order to analyse the differences of the effects of the above three assessment indexes on the potential damage categories of masonry structure, a comprehensive statistic comparison method is applied in the study, which is called one-way Analysis of Variance (ANOVA) [29]. This method is a kind of univariate analysis, which majorly studies if the difference of the one of the control variables has a significant influence on the total observed variables. Based on the theory studies of Lawal and Famoye [30], the mathematical model of one-way ANOVA is explained simply as follows:

(1) Assuming the control variable $\mathbf{A}$ has $k$ levels and each level has $r$ samples, the $j$ th sample $x_{i j}$ with $A_{i}$ control variable level is

$$
x_{i j}=\mu_{i}+\varepsilon_{i j} \quad i=1,2,3, \ldots, k ; j=1,2, \ldots, r,
$$

where $\mu_{i}$ is the theory value of the $A_{i}$ control variable and $\varepsilon_{i j}$ is random sampling error.

(2) Assume $u$ is the total theory value of control variable A, which is expressed as follows:

$$
\mu=\frac{1}{k} \sum_{i=1}^{k} \mu_{i} .
$$

(3) So the additional effect of control variables $A_{i}$ on the experimental results $\alpha_{i}$ is obtained and the total value of $\alpha_{i}$ is zero, given by

$$
\begin{aligned}
\alpha_{i} & =\mu_{i}-\mu, \quad i=1,2, \ldots, k, \\
\sum_{i=1}^{k} \alpha_{i} & =0 .
\end{aligned}
$$

(4) Based on (16) and (17), $x_{i j}$ is transferred as (19) and called mathematic model of the one-way ANOVA:

$x_{i j}=\mu+\alpha_{i}+\varepsilon_{i j}, \quad i=1,2, \ldots, k ; j=1,2, \ldots, r$.

(5) In the equation, the unbiased estimators of the total theory value of control variables $(\mu)$ and the additional effect of control variables $A_{i}$ on the experimental results $\left(\alpha_{i}\right)$ are

$$
\begin{aligned}
& \frac{\wedge}{\mu}=\bar{x} \\
& \frac{\wedge}{\alpha_{i}}=\overline{x_{i}}-\bar{x} .
\end{aligned}
$$

If control variable $A$ has an influence on observed variables, at least one of the values of $\alpha_{i}$ is not zero. Otherwise, all of the values of $\alpha_{i}$ are zero. The detailed analysis is called $F$ test analysis, whose completed steps are as follows: 

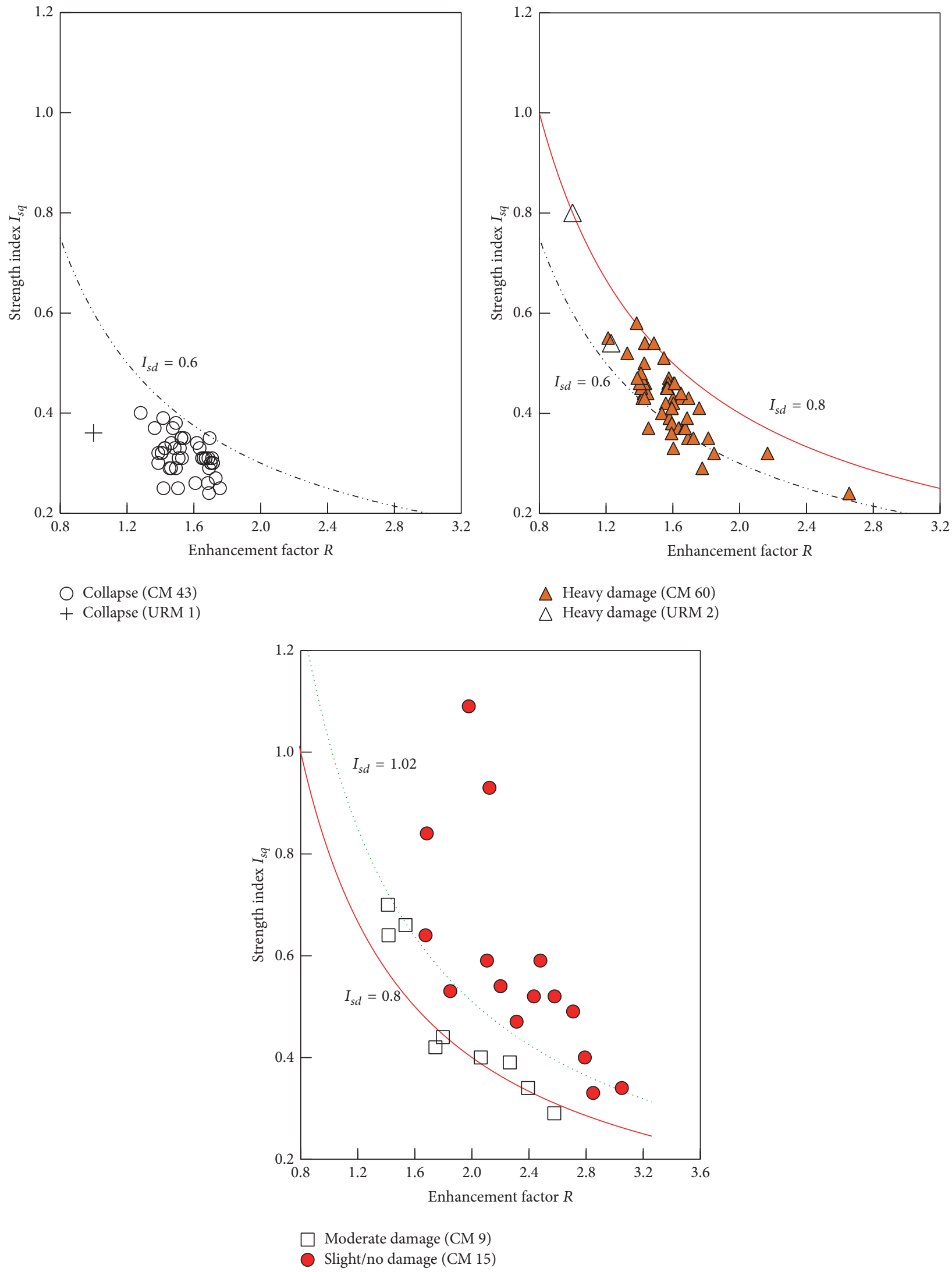

FIGURE 4: $I_{s d}$ and damage categories of the masonry building in seismic intensity IX zone. 
(1) Firstly, two null hypotheses are proposed, that is, $H_{\text {accept }}$ and $H_{\text {object }}$.

(2) Then, calculate the selection test statistic $F$ value, which is defined as

$$
F=\frac{\mathrm{SSA} /(k-1)}{\mathrm{SSE} /(m-k)}=\frac{\mathrm{MSA}}{\mathrm{MSE}} .
$$

In this equation, $m$ is total number of samples; SSA is the sum of squares between groups; SSE is the sum of squares in the groups; $k-1$ and $m-k$ are the freedom degree of SSA and SSE; MSA is the sum of squares of between the average values groups; MSA is the sum of squares of in the average values groups. The standard value of $F$ is from $F$-distribution having $(k-1, m-k)$ of freedom degree.

(3) Compare $F$ value and probability $P$ value; when the observed $F$ value is greater than 1 , that means the control variables have a significant impact on the observed variables; otherwise the impact is not significant. Additionally, the larger $F$ value is, the more significant the effect is.

Based on the above, one-way ANOVA is performed to study the effects of the damage categories on the three proposed indexes $I_{w}, I_{s q}$, and $I_{s d}$ at different seismic intensity zone. Here, as an example, the one in seismic intensity IX zone is presented in the study. A statistical package for the social sciences statistical program (SPSS) was used and four damage groups were created in the one-way ANOVA study (group 1 collapse damage, group 2 heavy damage, group 3 moderate damage, and group 4 slight or no damage). Firstly, it was assumed a single experiment variable (main control variable) has $k$ levels in the ANOVA, that is, the above damage degree. Based on this, the value of $k$ equals 4 . Therefore, the test level of overall significance is obtained using the following hypotheses:

$$
\begin{aligned}
& H_{\text {object }}: \alpha_{1}=\alpha_{2}=\alpha_{3}=\alpha_{4}=0 . \\
& H_{\text {accept }}: \text { at least one of the values of } \alpha_{k} \text { is not equal to } \\
& \text { zero. }
\end{aligned}
$$

Subsequently, the above hypotheses were performed and determined by comparing computed $F$ value and the critical one in one-way ANOVA [31]. The critical values of $F$ were obtained according to some statistic variables of specimen database. On the other hand, in some cases, the computed $F$ values are close which means the difference is not obvious. For these reasons, in this study, the proportion of variance $\left(\eta^{2}\right)$ was also used in the comparison which was provided by McClave and Sincich [31], given by

$$
\eta^{2}=\frac{\mathrm{SS}_{\text {Between Groups }}}{\mathrm{SS}_{\text {Total }}},
$$

where $\mathrm{SS}_{\text {Between Groups }}$ is the sum of squares of between groups and $\mathrm{SS}_{\text {Total }}$ is the sum of squares in total.
5.2. Multiple Comparisons: Scheffés Method. If the hypothesis is rejected as a result of one-way analysis of variance, it namely means that the various levels of assessment indexes are significantly different. However, this only shows that at least a difference between the two levels of assessment indexes is significant and it cannot say that there are significant differences between any two levels of the assessment indexes with the damage degree. For more than three assessment indexes, it often needs to determine where the specific significant differences are, that is, between which levels are the assessment indexes found. Therefore, if a refusal result was obtained from the analysis of one-way ANOVA, the further comparison should be finished for any difference between any two average groups from a number of average groups. This method is generally named multiple-comparison. The common method of multiple comparisons has Tukey-Kramer's and Scheffé's method. Tukey-Kramer method is better when only a fixed number of pairwise comparisons are to be made which will result in a more precise confidence interval. Scheffé's method is more appropriate to the cases having a large number of comparisons, on the other hand, when there are many or all contrasts in samples. Therefore, in this study, Scheffé's method was used in the following comparison.

Firstly, the mathematical model of Scheffé's method [32, 33 ] is illustrated as follows:

(1) When the evaluation result of one-way ANOVA is to reject the hypotheses, that is, the various levels of assessment indexes are significantly different, the difference between the $i$ th and $j$ th groups can be compared via using a calculated $S$ value which is defined as

$$
S=\frac{\max _{1 \leq i, j \leq r}\left|\bar{X}_{i}-\bar{X}_{j}\right|}{\sqrt{\operatorname{MSE}\left(1 / n_{i}+1 / n_{j}\right)}} .
$$

(2) The fractile quantile of $S$ value $\left(S_{a}\right)$ can be obtained from $S$-table or from the following equation:

$$
S_{a}=\sqrt{(r-1) F_{\alpha}(r-1, n-r)} .
$$

(3) Similar to the steps in one-way ANOVA, the steps of Scheffé's method are as follows:

(a) Firstly, a null hypothesis is proposed:

$$
\begin{aligned}
& H_{0}: \mu_{i}=\mu_{j}, i \neq j, i, j=1,2,3,4, \ldots, r . \\
& H_{1}: H_{0} \text { is not correct. }
\end{aligned}
$$

(b) Calculate $S_{a}$ based on (24) or from $S$-table and then calculate $T_{i j}$ which is defined as

$$
T_{i j}=S_{a} \sqrt{\frac{n_{i}+n_{j}}{n_{i} n_{j}}} .
$$

(c) Compare $T_{i j}$ and the absolute difference value of $d_{i j}$ between sample and average values. $d_{i j}$ is defined as

$$
\left|d_{i j}\right|=\left|x_{i}-x_{j}\right|
$$


TABLE 2: Comparison of the results of one-way ANOVA (seismic intensity IX zone).

\begin{tabular}{|c|c|c|c|c|c|c|c|}
\hline Indexes & Sum of squares & $\mathrm{df}$ & Mean square & Calculated $F$ value & Critical $F$ value & $\begin{array}{l}\text { Proportion of } \\
\text { variance }\left(\eta^{2}\right)\end{array}$ & Sig. \\
\hline \multicolumn{8}{|l|}{$I_{w}$} \\
\hline Between groups & $3.25 E+09$ & 3 & $1.08 E+09$ & 29.735 & 2.6 & $3.98 E-01$ & 0 \\
\hline Within groups & $4.92 E+09$ & 135 & $3.64 E+07$ & & & & \\
\hline Total & $8.17 E+09$ & 138 & & & & & \\
\hline \multicolumn{8}{|l|}{$I_{s q}$} \\
\hline Between groups & 3.629 & 3 & 1.21 & 40.282 & 2.6 & $4.72 E-01$ & 0 \\
\hline Within groups & 4.054 & 135 & 0.03 & & & & \\
\hline Total & 7.683 & 138 & & & & & \\
\hline \multicolumn{8}{|l|}{$I_{s d}$} \\
\hline Between groups & 14.772 & 3 & 4.924 & 176.008 & 2.6 & $7.96 E-01$ & 0 \\
\hline Within groups & 3.777 & 135 & 0.028 & & & & \\
\hline Total & 18.548 & 138 & & & & & \\
\hline
\end{tabular}

If the absolute difference value of $d_{i j}$ is greater than $T_{i j}$, that means there is an obvious difference between the $i$ th and $j$ th groups; otherwise, their difference is not significant.

5.3. Comparison and Discussion. Using the above two comparison methods, the three indexes are compared in detail. In this study, only the results in seismic intensity IX zone are presented, as a representative result. The other comparison can be reached at the detailed research report from the authors [34].

5.3.1. One-Way ANOVA. Table 2 shows the one-way ANOVA comparison results of the assessment results of these indexes. There are four groups which were used in the analysis, that is, collapse, heavy damage, moderate damage, and slight or no damage. Results show that the critical values of $F$ were both taken as 2.60 for the two indexes $I_{w}$ and $I_{s d}$ according to the values of $\mathrm{df}$ [31]. The results also indicate that the calculated $F$ value in the ANOVA is 29.74, which is larger than its critical value. Therefore, the hypotheses is rejected strongly which means index $I_{w}$ has a significant effect on the damage categories of masonry structures. In other words, index $I_{w}$ can be used to clearly distinguish or predict the potential damage categories of the masonry buildings in seismic intensity IX zone. Comparing with the results of index $I_{w}$, however, the computed $F$ values of indexes $I_{s q}$ and $I_{s d}$ are better and reach 40.28 and 176.008, respectively. This implies that index $I_{s d}$ has a more significant influence on the damage categories of surveyed masonry structures. On the other hand, the significance degrees (Sig.) of these indexes all are equal to zero, meaning that they all have significant influences on the damage degree of masonry structures. Besides, the result shows that the value of $\eta^{2}$ for indexes $I_{w}, I_{s q}$, and $I_{s d}$ are 0.39, 0.47 , and 0.79 , respectively. This illustrates that the combined assessment index $I_{s d}$ is the best index to predict the potential damage categories of the masonry buildings in earthquakeprone zone. In summary, comparing other indexes, $I_{s d}$ has the largest computed $F$ value, which means the index has the most significant influence on the damage levels of these masonry buildings.

5.3.2. Scheffés Comparison. Table 3 shows the results of Scheffé's analysis comparison of the three indexes in seismic intensity IX zone. Firstly, regarding index $I_{w}$, the results present that there are significant difference between the first group (collapse) and other groups, because their probability $P$ values are less than 0.05 , a supposed significant level. Similar results are observed for the fourth group (slight or no damage). For the moderate and heavy damage group, however, they also present significant difference levels with other kinds of damage, except for each other, that is, the difference between them. In other words, they just can differentiate between the buildings with the collapse and slight/no damage groups, respectively. It indicates that $I_{w}$ is not able to differentiate the buildings with moderate and heavy damage. For the assessment index $I_{s q}$, similar results are confirmed to the ones of index $I_{w}$. The analysis results of the buildings with collapse and slight/no damage all show a significant difference with the corresponding three types of damage. However, comparing with the ones of index $I_{w}$, the $P$ values of the moderate damage group were improved which has no obvious difference with the heavy damage. Regarding the combined index $I_{s d}$, all damage groups present well a significant difference level with the other groups. The appearance probability of no difference between any two groups is zero which means this index effectively divides all kind of damage degrees including the moderate and heavy damage types for masonry structures in seismic intensity IX zone.

\section{Discussion and Recommendation}

Based on the above analyses, the combined index $I_{s d}$ is suggested to predict the potential damage of masonry structures when the detailed information of the used materials in the inspected structures is available. However, for the existing 
TABLE 3: Comparison of the results of Scheffé's analysis (seismic intensity IX zone).

\begin{tabular}{|c|c|c|c|c|c|c|c|}
\hline \multirow{2}{*}{ Indexes } & \multirow{2}{*}{ (I) group } & \multirow{2}{*}{$(J)$ group } & \multirow{2}{*}{ Mean difference $(I-J)$} & \multirow{2}{*}{ Std. error } & \multirow{2}{*}{ Sig. } & \multicolumn{2}{|c|}{ 95\% Confidence interval } \\
\hline & & & & & & Lower bound & Upper bound \\
\hline \multirow{12}{*}{$I_{w}$} & \multirow{3}{*}{1} & 2 & -3966.734 & 1186.070 & 0.013 & -7324.597 & -608.872 \\
\hline & & 3 & -5809.695 & 2035.044 & 0.047 & -11571.072 & -48.318 \\
\hline & & 4 & -15010.000 & 1601.164 & 0.000 & -19551.362 & -10485.308 \\
\hline & \multirow{3}{*}{2} & 1 & 3966.734 & 1186.070 & 0.013 & 608.872 & 7324.597 \\
\hline & & 3 & -1843.000 & 1972.715 & 0.832 & -7427.880 & 3741.958 \\
\hline & & 4 & -11050.000 & 1521.160 & 0.000 & -15358.130 & -6745.072 \\
\hline & \multirow{3}{*}{3} & 1 & 5809.695 & 2035.044 & 0.047 & 48.318 & 11571.072 \\
\hline & & 2 & 1842.961 & 1972.715 & 0.832 & -3741.958 & 7427.880 \\
\hline & & 4 & -9208.640 & 2246.902 & 0.001 & -15569.805 & -2847.476 \\
\hline & \multirow{3}{*}{4} & 1 & 15018.335 & 1601.164 & 0.000 & 10485.308 & 19551.362 \\
\hline & & 2 & 11051.601 & 1521.160 & 0.000 & 6745.072 & 15358.130 \\
\hline & & 3 & 9208.640 & 2246.902 & 0.001 & 2847.476 & 15569.805 \\
\hline \multirow{12}{*}{$I_{s q}$} & \multirow{3}{*}{1} & 2 & -0.120 & 0.034 & 0.007 & -0.217 & -0.024 \\
\hline & & 3 & -0.209 & 0.058 & 0.006 & -0.375 & -0.044 \\
\hline & & 4 & -0.498 & 0.046 & 0.000 & -0.629 & -0.368 \\
\hline & \multirow{3}{*}{2} & 1 & 0.120 & 0.034 & 0.007 & 0.024 & 0.217 \\
\hline & & 3 & -0.088 & 0.057 & 0.490 & -0.249 & 0.072 \\
\hline & & 4 & -0.377 & 0.044 & 0.000 & -0.501 & -0.254 \\
\hline & \multirow{3}{*}{3} & 1 & 0.209 & 0.058 & 0.006 & 0.044 & 0.375 \\
\hline & & 2 & 0.088 & 0.057 & 0.490 & -0.072 & 0.249 \\
\hline & & 4 & -0.289 & 0.065 & 0.000 & -0.472 & -0.107 \\
\hline & \multirow{3}{*}{4} & 1 & 0.498 & 0.046 & 0.000 & 0.368 & 0.629 \\
\hline & & 2 & 0.377 & 0.044 & 0.000 & 0.254 & 0.501 \\
\hline & & 3 & 0.289 & 0.065 & 0.000 & 0.107 & 0.472 \\
\hline \multirow{12}{*}{$I_{s d}$} & \multirow{3}{*}{1} & 2 & -0.181 & 0.033 & 0.000 & -0.274 & -0.088 \\
\hline & & 3 & -0.376 & 0.056 & 0.000 & -0.536 & -0.217 \\
\hline & & 4 & -0.992 & 0.044 & 0.000 & -1.118 & -0.867 \\
\hline & \multirow{3}{*}{2} & 1 & 0.181 & 0.033 & 0.000 & 0.088 & 0.274 \\
\hline & & 3 & -0.194 & 0.055 & 0.007 & -0.350 & -0.040 \\
\hline & & 4 & -0.811 & 0.042 & 0.000 & -0.930 & -0.692 \\
\hline & \multirow{3}{*}{3} & 1 & 0.376 & 0.056 & 0.000 & 0.217 & 0.536 \\
\hline & & 2 & 0.194 & 0.055 & 0.007 & 0.040 & 0.350 \\
\hline & & 4 & -0.616 & 0.062 & 0.000 & -0.792 & -0.440 \\
\hline & \multirow{3}{*}{4} & 1 & 0.992 & 0.044 & 0.000 & 0.867 & 1.118 \\
\hline & & 2 & 0.811 & 0.042 & 0.000 & 0.692 & 0.930 \\
\hline & & 3 & 0.616 & 0.062 & 0.000 & 0.440 & 0.792 \\
\hline
\end{tabular}

buildings without the detailed information of materials, indexes $I_{w}$ and $I_{s q}$ still can be used to predict the potential damage of the structures. Using the same methods reported above, the study also analyses the buildings located at the seismic intensity VIII and X zones of the 2008 Wenchuan earthquake. Through analysing the relationship between three proposed indexes and damage degree, some relevant suggestions of masonry structures built in seismic-prone zone are provided as follows.

6.1. Seismic Intensity and Damage. Through studying the relative increase indexes of the proposed three assessment indexes, the total damage characteristics of masonry structures in seismic intensity VIII, IX, and X zones are summarized. The analysis method is as follows:

(1) Suppose the index values of no collapse damage in seismic intensity VIII-X zones as $A_{1}-A_{3}$ and the ones of no heavy and moderate damage as $A_{4}-A_{6}$ and $A_{7}-A_{9}$, respectively. The detailed relationships between three assessment indexes and damage types of masonry buildings are presented in Figures 57. The detailed values of the indexes are reported elsewhere [34]. 




FIGURE 5: $I_{w}$ and the damage type of masonry structures.

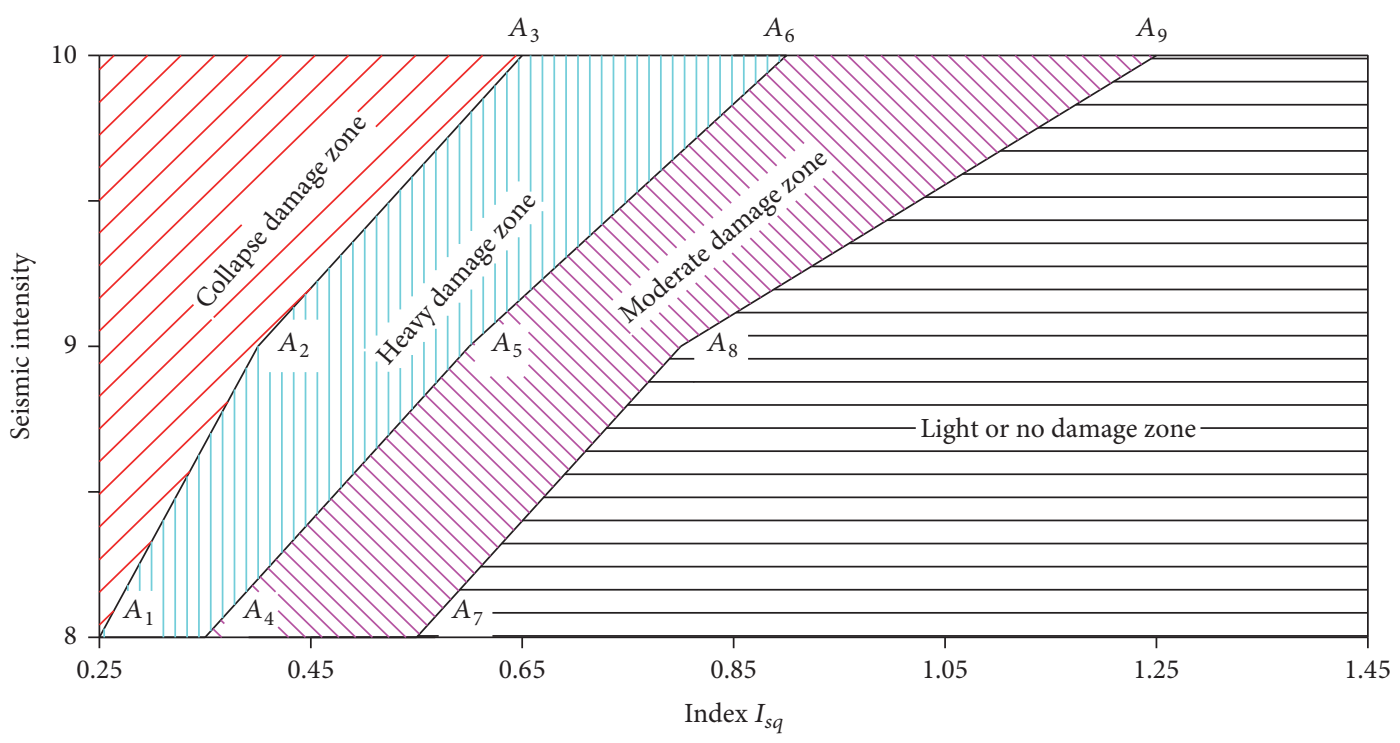

FIGURE 6: $I_{s q}$ and the damage type of masonry structures.

(2) According to these values of $A_{1}-A_{9}$ of the above three indexes, the relationships between them and the actual damage types of the masonry structures are obtained.

(3) Calculate and compare the relative increase indexes $m_{1}, m_{2}, m_{3}$, which are defined, respectively, as follows:

$$
\begin{aligned}
& m_{1}=\frac{A_{3}-A_{2}}{A_{2}-A_{1}}, \\
& m_{2}=\frac{A_{6}-A_{5}}{A_{5}-A_{4}}, \\
& m_{3}=\frac{A_{9}-A_{8}}{A_{8}-A_{7}} .
\end{aligned}
$$

For indexes $I_{w}$ and $I_{s q}$, according to the fact that indexes $m_{2}$ and $m_{3}$ are both greater than zero, the required values of $I_{w}$ and $I_{s q}$ of masonry structures should be increased to avoid their similar level of damage when their seismic intensity changes from VIII to IX or IX to X. Meanwhile, $m_{3}>m_{2}$, $m_{3}>1.0$, and it indicates that the increase in amplitude of the required values of $I_{w}$ and $I_{s q}$ of the masonry buildings to avoid their moderate damage is higher than the one to avoid the heavy damage. For the combined index $I_{s d}$, the values of $m_{1}-$ $-m_{3}$ are $1.5,2.5$, and 3.5 , respectively. It means the required levels of $I_{s d}$ of masonry structures to avoid the corresponding damage type increase as the seismic intensity. Meanwhile, the case $m_{3}>m_{2}>m_{1}>1.0$ indicates that the increase in amplitudes of the required $I_{s d}$ of masonry structures to avoid 


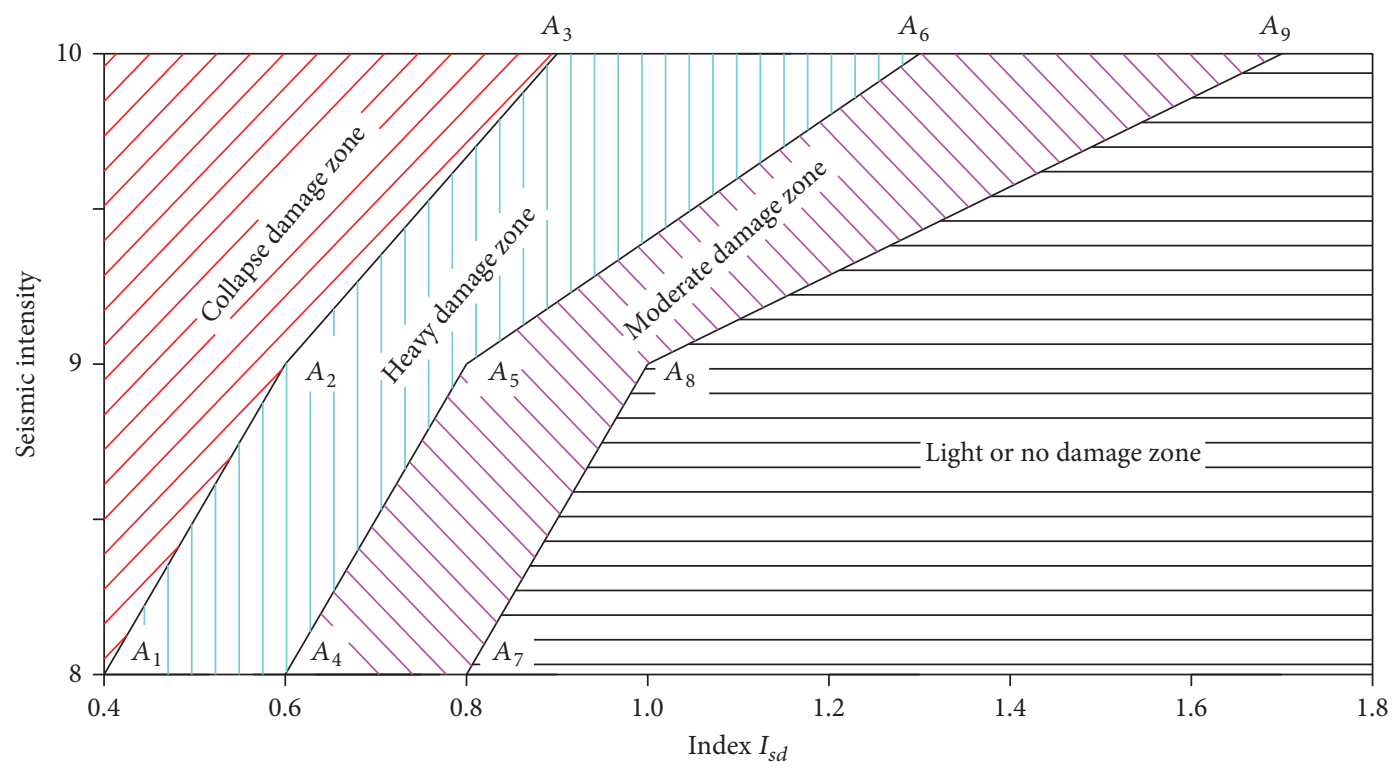

FIGURE 7: $I_{s d}$ and the damage type of masonry structures.

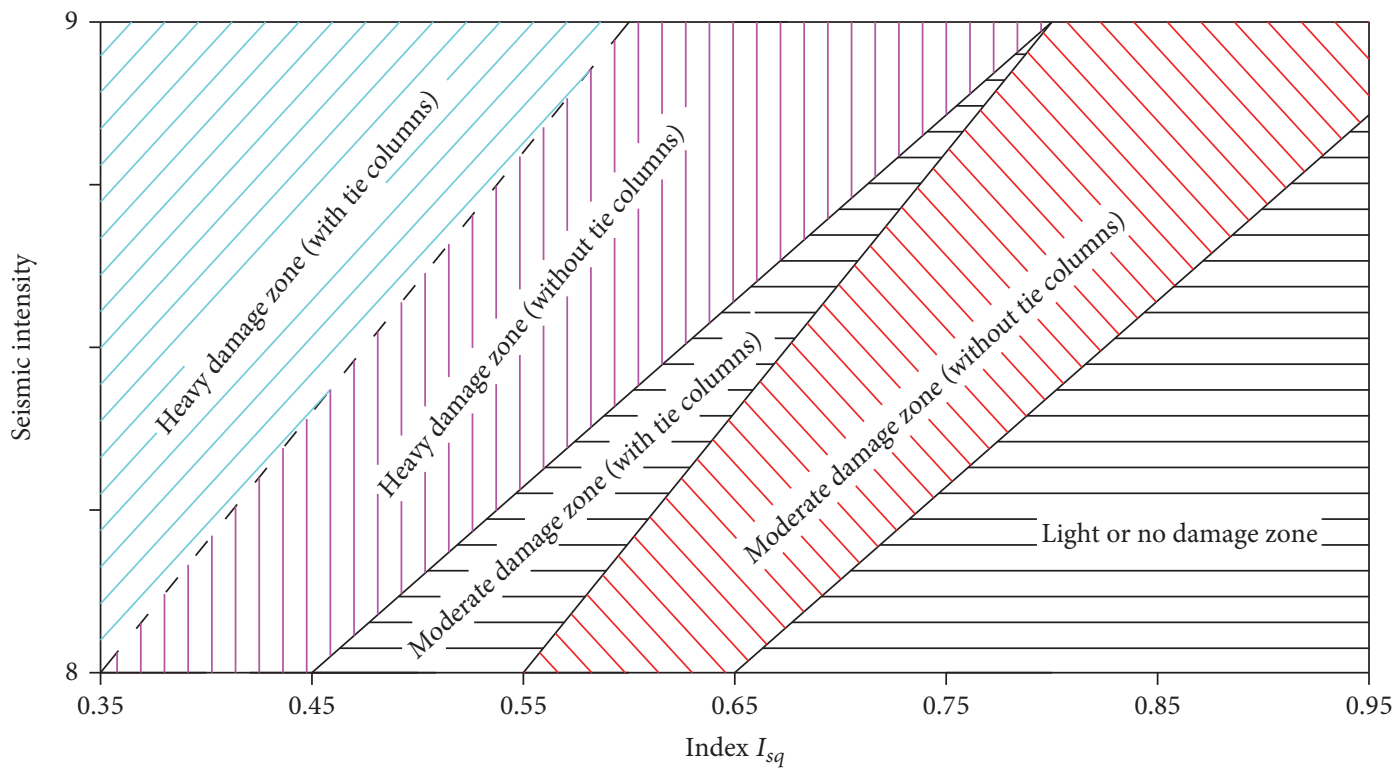

FIGURE 8: $I_{s q}$ and the damage type of masonry structures with/without tie columns.

their moderate damage (heavy damage) is higher than the one of the buildings to avoid their heavy damage (collapse damage). On the other hand, the above studies on the strength and combined indexes also indicate that to reduce the number of building story of masonry structures is a good way to increase the seismic resistance capacity of total masonry building, and to use more confinement element such as tie columns is a good way to improve the capacity and deformation of total structures as well. However, the implementation of the two ways is limited for the wall density which is majorly dependent on the plan distribution and use function of masonry structures; in addition, the number of building storeys is preset by users, and it cannot be changed by designers or engineers. It is difficult to avoid the appearance of damage in the masonry structures in high seismic intensity zone, especially the slight or moderate damage, because the increase of confinement elements and the increased requirement of wall density both are limited.

6.2. Application of Tie Columns in Masonry Structures. Comparing with the result in Figure 5, the result plotted in Figure 8 clearly shows the positive influence of tie columns in masonry structures. These columns can effectively improve the total properties of masonry structures and enhance the confinement of masonry wall, which both are good for the resistant of masonry walls during an earthquake, in particular 
for the masonry buildings with potential moderate and heavy damage.

\section{Conclusions}

This paper studied the relationship between three potential assessment indexes with the actual damage degrees of 130 surveyed masonry buildings in the 2008 Wenchuan earthquake and presented the application of variance analyses comparison in the determination of the optimum seismic damage assessment method of masonry buildings using three simplified indexes. For this end, one-way analysis of variance and Scheffé's method were used to compare comprehensively the feasibility of the three indexes. The main conclusion can be drawn as follows:

(1) From the viewpoint of mathematical statistics, the three assessment indexes proposed in the study all present discrimination in certain degree for the masonry structures having the same damage level. This means the indexes can be used to predict the potential damage types of masonry structures, especially for combined index considering strength of used materials and enhancement influence of confinement elements of masonry structures.

(2) The $F$ value of the strength index $I_{s q}$ is higher comparing with that of wall density index $I_{w}$. This means the index presents a more obvious difference between four types of damage; however, the difference between moderate and heavy damage is small.

(3) After combining with the enhancement factor of confinement elements in masonry structures, index $I_{s d}$ has the highest $F$ value. Comparing the other two indexes, when evaluating the potential damage type of masonry structures, this index shows a more obvious distinction degree and difference between each damage level, including all four damage types.

(4) Based on the comparison and analyses, the study indicated that to reduce the number of building storeys of masonry structures is a good way to increase seismic resistance capacity of total building and to use more confinement elements such as more tie columns/beams is a good way to improve the seismic behaviour of total structures. It is difficult to avoid the appearance of damage in the masonry structures in high seismic intensity zone, especially the slight or moderate damage because the increase of confinement elements and the increased requirement of wall density both are limited.

(5) Univariate comparison analysis can be used to determine simply and fast the superiority of the three proposed assessment indexes in distinguishing capacity of the damage degree of masonry buildings such as the one-way analysis of variance. Multiplecomparison analysis is more complex but can provide a more direct and detailed comparison of the difference between any two kinds of damage levels.
(6) To resist of the damage of masonry walls during an earthquake, in particular for the buildings with potential moderate and heavy damage, the addition of tie columns is good way for it can effectively improve the total seismic properties of masonry structures and enhance the confinement of masonry wall.

(7) Since the number of URM buildings is small in the inspected database of the paper, it should be noted that the results regarding URM structures may be verified further, meaning more field investigations are expected.

\section{Competing Interests}

The authors declare that they have no competing interests.

\section{Acknowledgments}

The authors gratefully acknowledge the support of the National Natural Science Foundation of China (Grant no. 51308473).

\section{References}

[1] Sina New, 2008 http://news.sina.com.cn/pc/2008-05-13/326 /651.html.

[2] National Police Agency of Japan, 2016, http://www.npa.go.jp/ archive/keibi/biki/higaijokyo_e.pdf.

[3] V. Kim, "Japan damage could reach \#35 billion, World Bank estimates," Los Angeles Times, March 2011.

[4] GB 50003-2011, Code for Design of Masonry Structures, China Architecture \& Building Press, Beijing, China, 2011 (Chinese).

[5] NCH 2123, Confined Masonry-Requirement for Structural Design, INN, Santiago, Chile, 2003.

[6] BS EN 1996-1-1, Eurocode 6-Design of Masonry Structures, BSI, London, UK, 2005.

[7] P. G. Asteris, M. P. Chronopoulos, C. Z. Chrysostomou et al., "Seismic vulnerability assessment of historical masonry structural systems," Engineering Structures, vol. 62-63, pp. 118134,2014

[8] B. Jin, M. Z. Zhang, X. Guo et al., "Structural analysis and constructional measures for earthquake resistant buildings," World Earthquake Engineering, vol. 25, no. 2, pp. 68-71, 2009 (Chinese).

[9] M. Bruneau, "State-of-the-art report on seismic performance of unreinforced masonry buildings," Journal of Structural Engineering, vol. 120, no. 1, pp. 230-251, 1994.

[10] G. Magenes and G. M. Calvi, "In-plane seismic response of brick masonry walls," Earthquake Engineering \& Structural Dynamics, vol. 26, no. 11, pp. 1091-1112, 1997.

[11] R. Marques and P. B. Lourenço, "A model for pushover analysis of confined masonry structures: implementation and validation," Bulletin of Earthquake Engineering, vol. 11, no. 6, pp. 21332150, 2013.

[12] Y. Belmouden and P. Lestuzzi, "An equivalent frame model for seismic analysis of masonry and reinforced concrete buildings," Construction and Building Materials, vol. 23, no. 1, pp. 40-53, 2009. 
[13] A. H. Akhaveissy, "Finite element nonlinear analysis of highrise unreinforced masonry building," Latin American Journal of Solids and Structures, vol. 9, no. 5, pp. 547-567, 2012.

[14] P. Medeiros, G. Vasconcelos, P. B. Lourenço, and J. Gouveia, "Numerical modelling of non-confined and confined masonry walls," Construction and Building Materials, vol. 41, pp. 968-976, 2013.

[15] P. B. Lourenço and J. A. Roque, "Simplified indexes for the seismic vulnerability of ancient masonry buildings," Construction and Building Materials, vol. 20, no. 4, pp. 200-208, 2006.

[16] M. Vailati, G. Monti, and G. di Gangi, "Seismic assessment of masonry building clusters with a dedicated NLA software," Applied Mechanics and Materials, vol. 847, pp. 191-203, 2016.

[17] P. B. Lourenço, D. V. Oliveira, J. C. Leite, J. M. Ingham, C. Modena, and F. da Porto, "Simplified indexes for the seismic assessment of masonry buildings: international database and validation," Engineering Failure Analysis, vol. 34, pp. 585-605, 2013.

[18] D. Celarec, P. Ricci, and M. Dolšek, "The sensitivity of seismic response parameters to the uncertain modelling variables of masonry-infilled reinforced concrete frames," Engineering Structures, vol. 35, pp. 165-177, 2012.

[19] M. Vailati, G. Monti, M. J. Khazna, A. Napoli, and R. Realfonzo, "Probabilistic assessment of masonry building clusters," in Proceedings of the 15th WCEE-World Conference of Earthquake Engineering, Lisbon, Portugal, 2012.

[20] M. Preti, V. Bolis, and A. Stavridis, "Design of masonry infill walls with sliding joints for earthquake structural damage control," in Proceedings of the 16th International Brick and Block Masonry Conference (IBMAC '16), Padova, Italy, June 2016.

[21] K. A. G. Franch, G. M. G. Morbelli, M. A. A. Inostroza, and R. E. Gori, "A seismic vulnerability index for confined masonry shear wall buildings and a relationship with the damage," Engineering Structures, vol. 30, no. 10, pp. 2605-2612, 2008.

[22] J. Ruiz-García and M. Negrete, "Drift-based fragility assessment of confined masonry walls in seismic zones," Engineering Structures, vol. 31, no. 1, pp. 170-181, 2009.

[23] D. T. Zhong, J. C. Dong, and X. Wu, "Experimental study on seismic behavior of brick buildings models and walls with tie RC columns," Building Science, vol. 2, no. 4, pp. 53-61, 1986 (Chinese).

[24] M. Tomaževič and I. Klemenc, "Seismic behaviour of confined masonry walls," Earthquake Engineering and Structural Dynamics, vol. 26, no. 10, pp. 1059-1071, 1997.

[25] R. Meli, S. Brzev, M. Astroza et al., Seismic Design Guide for LowRise Confined Masonry Buildings, EERI \& IAEE, Oakland, Calif, USA, 2011.

[26] GB/T 24335-2009, Classification of Earthquake Damage to Buildings and Special Structures, China Standard Press, Beijing, China, 2009 (Chinese).

[27] Japan Building Disaster Prevention Association (JBUPA), Seismic Evaluation and Retrofit (English Version), Japan Building Disaster Prevention Association (JBUPA), Tokyo, Japan, 2001.

[28] Japan Building Disaster Prevention Association (JBUPA), Standard for Seismic Evaluation of Existing Reinforced Concrete Buildings, Japan Building Disaster Prevention Association (JBUPA), Tokyo, Japan, 2001 (Japanese).

[29] R. Ho, Handbook of Univariate and Multivariate Data Analysis with IBM SPSS, CRC Press, 2013.

[30] B. Lawal and F. Famoye, Applied Statistics: Regression and Analysis of Variance, University Press of America, 2013.
[31] J. T. McClave and T. Sincich, A First Course in Statistics, Pearson Education, Upper Saddle River, NJ, USA, 10th edition, 2009.

[32] S. E. Maxwell and H. D. Delaney, Designing Experiments and Analyzing Data: A Model Comparison Perspective, vol. 1, Psychology Press, Hove, UK, 2004.

[33] G. A. Milliken and D. E. Johnson, Analysis of Messy Data Volume 1: Designed Experiments, vol. 1, CRC Press, Boca Raton, Fla, USA, 2009.

[34] Q. W. Su, Seismic evaluation of masonry structures [Ph.D. thesis], Southwest Jiaotong University, 2011. 


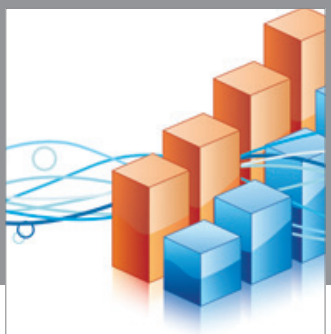

Advances in

Operations Research

vatem alat4

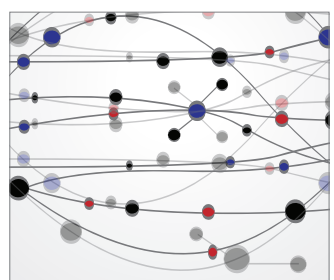

\section{The Scientific} World Journal
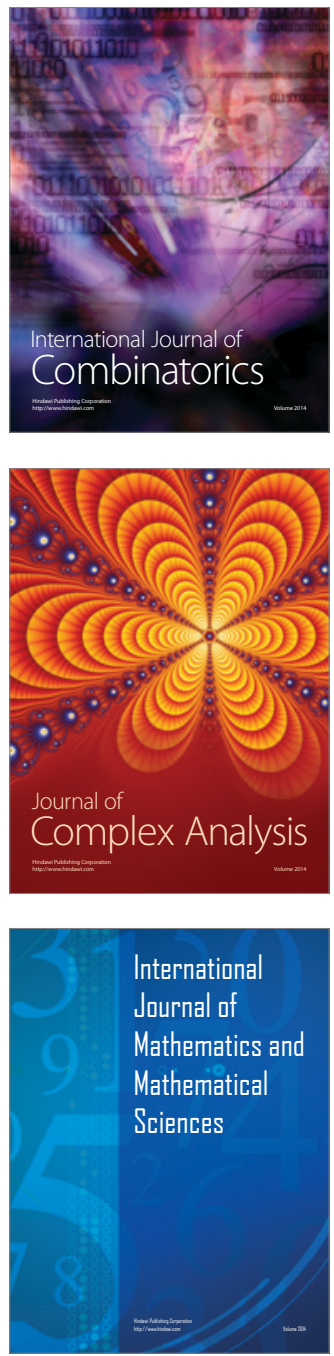
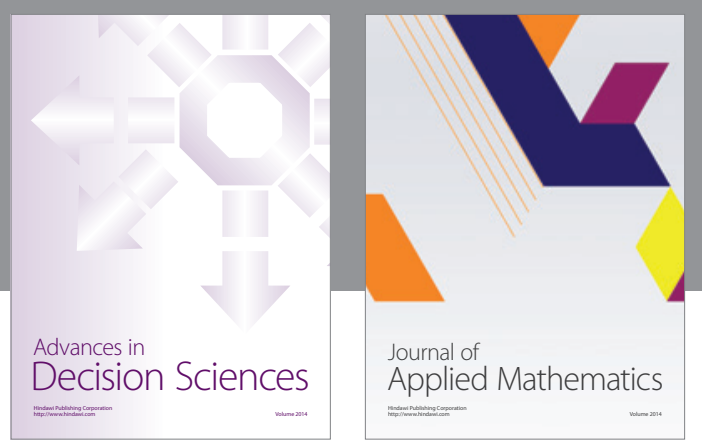

Algebra

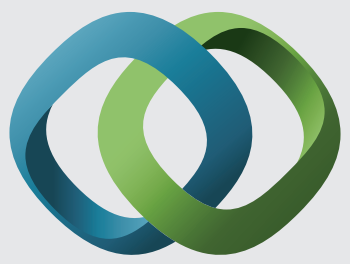

\section{Hindawi}

Submit your manuscripts at

https://www.hindawi.com
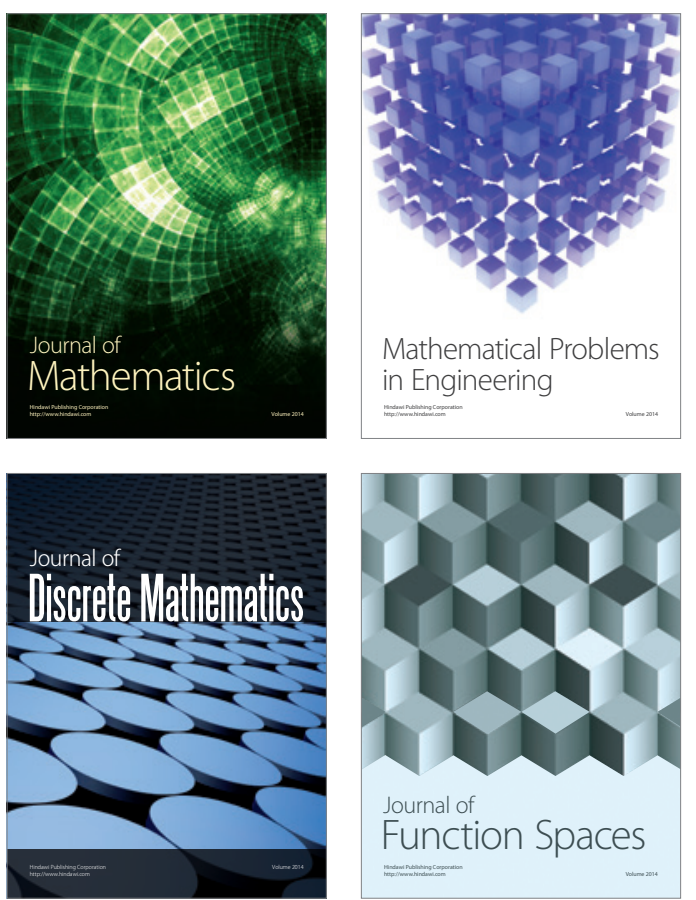

Mathematical Problems in Engineering
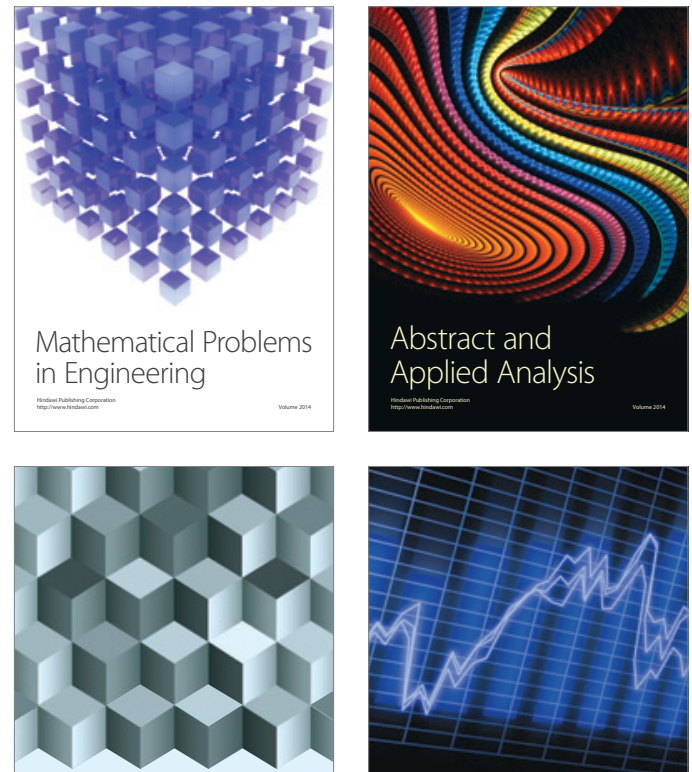

Journal of

Function Spaces

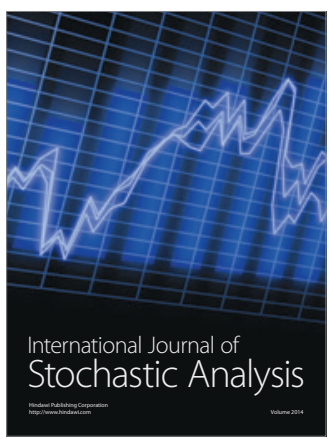


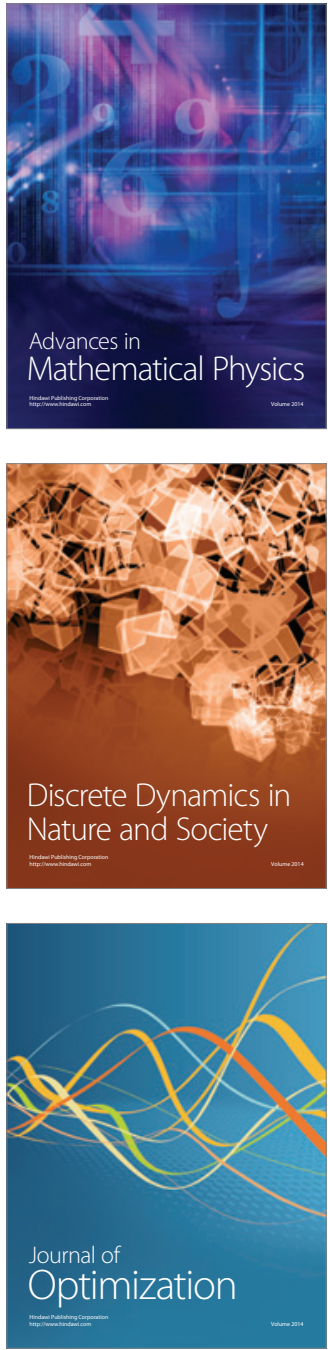